\section{Bioética e diálise: uma revisão integrativa}

DINIZ, DF ${ }^{1}$

SOUSA, FF $^{1}$

HANNES, IE ${ }^{1}$

PEREIRA, RS ${ }^{1}$

${ }^{1}$ Acadêmicos do curso de Medicina do Centro Universitário de Brasília (UniCEUB).Contato: deboraffdiniz@gmail.com

\section{FERRAZ, F.H.R.P}

Professor Adjunto de Medicina do Uniceub. Doutorando do PPG em Bioética - Universidade de Brasília

PALAVRAS CHAVES: bioética, diálise, diálise peritoneal, diálise renal, ética médica.

INTRODUÇÃO: Doença renal crônica dialítica é considerada um problema de saúde pública, sobretudo nos países em desenvolvimento, devido a crescente prevalência e elevado impacto econômico para manutenção dos pacientes em tratamento. As implicações bioéticas do tratamento hemodialítico são inúmeras, devendo-se considerar a participação dos fatores de vulnerabilidade de origem biológica, ambiental ou econômica, como escassez de investimentos em saúde, condições sanitárias precárias, transição demográfica recente e alta prevalência de doenças infectocontagiosas. Estes podem aumentar o risco de desenvolvimento da DRC, dificultar adesão ao tratamento e aumentar a morbimortalidade, resultando em diagnósticos tardios e tratamentos complexos. Atendimento ao paciente com DRC inclui também acesso a medicamentos, transporte, internação hospitalar e espera na lista para transplante renal, responsáveis por grande impacto na qualidade de vida. Assim, utilizando princípios bioéticos, avalia-se a iniciação e manutenção de intervenções terapêuticas. Autonomia referese ao direito do indivíduo de tomar decisões relacionadas sobre sua vida e tratamento, sendo melhor exercida por pacientes esclarecidos, processo com participação direta dos profissionais da saúde. Justiça aborda acesso equitativo ao tratamento, sem discriminação ou marginalização. Beneficência está ligada à atuação dos profissionais, que devem procurar melhorar o bem-estar do paciente enquanto respeitam o princípio da não-maleficência, evitando danos e intervenções que ultrapassem o benefício. Neste contexto, o trabalho em questão objetiva analisar as temáticas envolvendo bioética e diálise na literatura internacional. METODOLOGIA: Trata-se de uma revisão integrativa com a temática dos princípios da bioética no processo de diálise. A busca foi realizada nas bases de dados Google Acadêmico, LILACS, PubMed e Scielo com os seguintes descritores: Bioética, Brasil, Diálise, Diálise Peritoneal, Diálise Renal, Doença Renal Crônica, Insuficiência Renal Crônica, como também seus respectivos em inglês, com delimitação temporal de 2008-2018. Foram encontrados 445 artigos, de acordo com a recomendação Prisma, sendo utilizados como critérios de exclusão trabalhos repetidos, estudos não transversais, ano de publicação e inadequação ao tema. Ao final, foram selecionados 11 artigos adequados aos critérios. RESULTADOS: Dentre os estudos transversais, encontraram-se pesquisas descritivas $(n=6)$ e exploratórias $(n=5)$, com enfoque qualitativo, dois apresentaram, também, abordagem qualitativa. Foi observada, em quatro artigos (36,3\%), uma análise dos quatro princípios bioéticos na conduta e manejo da diálise; em três $(27,3 \%)$, o respeito a autonomia e, em dois $(18,2 \%)$, a importância da justiça. Vulnerabilidade e seu impacto na redução da qualidade de vida se encontram em três estudos (27,3\%), evidenciando um estado de conformação com o procedimento sem real conhecimento de terapêuticas alternativas. Qualidade de vida foi a temática central em 5 artigos (45,5\%). Evidencia-se também a importância do ensino dos princípios bioéticos para especialistas e residentes em nefrologia, impactando no melhor cumprimento da bioética. CONCLUSÃO: A despeito da importância do assunto no cenário nefrológico internacional, não houve um número expressivo de artigos com a interface entre bioética e nefrologia nos últimos 10 anos, o que reforça a necessidade do ensino da bioética entre especialistas e profissionais de nefrologia, como maneira de permitir um melhor entendimento dos dilemas éticos e permitindo um melhor reconhecimento da vulnerabilidade dos pacientes e de um tratamento mais humanizado.

\section{AGRADECIMENTOS}

Agradecemos à instituição UniCEUB e seu corpo docente, que nos incentivam e preparam de forma ética e competente para a vida acadêmica-profissional. À Liga Acadêmica de Nefrologia do UniCEUB (LANEFRU) pela oportunidade de conhecer a área de nefrologia, contribuindo para o desenvolvimento cientifico e aprofundamento nessa especialidade. Ao orientador, Dr Fábio Ferraz, pelo direcionamento e contribuição para a realização deste.

\section{REFERÊNCIAS}

[1] BUTLER, Catherine R. et al. The evolving ethics of dialysis in the United States: a Principlist bioethics approach. Clinical Journal of the American Society of Nephrology, p. CJN. 04780515, 2016.

[2] COUTINHO, Nair Portela Silva; TAVARES, Maria Clotilde Henriques. Atenção ao paciente renal crônico, em hemodiálise, sob a ótica do usuário.Cad. saúde colet., (Rio J.); 19(2)abr. 2011. Tab

[3] FERRAZ, Fábio Humberto Ribeiro Paes et al. Diferenças e desigualdades no acesso a terapia renal substitutiva nos países do BRICS. Ciência \& Saúde Coletiva, v. 22, p. 21752185, 2017.

[4] SALATI, Maria Inês; HOSSNE, William Saad; PESSINI, Leocir. Vulnerabilidade referida pelos pacientes renais 
crônicos-considerações bioéticas. Bioethikos, v. 5, n. 4, p. 434-42, 2011

[5] TORRALBA MADRID, M. J.; PÉREZ GÁZQUEZ, I.

M. La calidad de vida del paciente nefrológico desde la perspectiva bioética. Enfermería Global, v. 10, n. 24, p. 0-0, 2011. 